\title{
Economic Outcomes Associated with Safety Interventions by a Pharmacist-Adjudicated Prior Authorization Consult Service
}

\author{
Sherin Jacob, PharmD, BCPS; Rachel B. Britt, PharmD, BCPS; William E. Bryan, PharmD, BCPS; \\ Mohamed G. Hashem, PharmD, BCPS; Jonathan C. Hale, PharmD, BCPS; \\ and Jamie N. Brown, PharmD, BCPS, BCACP
}

\begin{abstract}
BACKGROUND: The establishment of a formulary management system ensures that health care professionals work together in an integrated patient care process to promote clinically sound, safe, and cost-effective medication therapy. Pharmacists have a foundational role within this system. A pharmacist-adjudicated prior authorization drug request (PADR) consult service has the potential to optimize drug therapy by decreasing medication misuse, minimizing adverse drug events (ADEs), and preventing medication errors.
\end{abstract}

OBJECTIVES: To (a) determine cost avoidance associated with pharmacistadjudicated PADR safety interventions within the Durham Veterans Affairs Health Care System and (b) evaluate cost savings associated with pharmacist-adjudicated PADRs not approved due to a safety intervention, evaluate cost avoidance and direct cost savings based on clinical specialty of pharmacist adjudicating PADR, and characterize severity of avoided ADEs.

METHODS: Pharmacist-adjudicated PADRs not approved between July 1, 2016, and June 30, 2017, because of safety interventions were retrospectively reviewed. Cost avoidance was determined by multiplying the probability of ADE occurrence in the absence of PADR safety intervention by the estimated cost avoided based on the type of intervention. Direct cost savings was calculated by totaling the cost of requested medications not approved for each PADR and subtracting the cost of recommended alternative therapies and cost of pharmacist PADR review. All potential ADEs avoided were reviewed by a panel of 3 clinical pharmacists to validate ADE classification and ADE probability and severity scores. Descriptive statistics were used for all analyses.

RESULTS: Of the 910 PADRs that were not approved during the study period, 96 met inclusion criteria. Pharmacist-adjudicated PADR safety interventions resulted in a total cost avoidance of $\$ 24,485.34$ (mean $=\$ 255.06$ ) and a direct cost savings of $\$ 288,695.63$ (mean $=\$ 3,007.25$ ). The practice settings of anticoagulation and infectious diseases PADRs resulted in the largest contribution to cost avoidance and direct cost savings, respectively. Prevented ADEs were classified as major for $64.6 \%$ of the PADRs.

CONCLUSIONS: Pharmacist-adjudicated PADR safety reviews resulted in substantial economic benefit and prevention of major ADEs. This analysis supports the pharmacist's role in a formulary management system to optimize medication therapy.

J Manag Care Spec Pharm. 2019;25(3):411-16

Copyright @ 2019, Academy of Managed Care Pharmacy. All rights reserved.

\section{What is already known about this subject}

Formulary management, an integrated patient care process routinely used by several health care organizations, enables health care professionals to use a methodological approach to promote costeffective medication therapy and positive therapeutic outcomes. A pharmacist-adjudicated formulary management consult service in a Veterans Affairs (VA) medical center has been associated with substantial cost savings after incorporating the cost of a pharmacist review.

\section{What this study adds}

This study evaluates the cost avoidance, direct cost savings, and safety impact associated with pharmacist-adjudicated PADR safety interventions within a VA health care system.

A pharmacist-adjudicated prior authorization drug request (PADR) consult service in a VA health care system resulted in substantial cost avoidance, direct cost savings, and the prevention of adverse drug events, the majority of which were classified as severe.

This economic and safety analysis supports the value of a pharmacist in a formulary management system to optimize medication therapy.

T he establishment of a central formulary management system within a health care system ensures that medications are selected based more on safety and efficacy than cost. ${ }^{1}$ Organizations such as the Institute for Safe Medication Practices provide guidance on strategic planning efforts to ensure medication safety and emphasize the importance of establishing a controlled formulary to review and evaluate drugs with error potential before approval., ${ }^{1,2}$ A drug formulary consists of a continuously updated preferred drug list reviewed by physicians, pharmacists, and experts and is ultimately supported by evidence-based medicine. A formulary management system uses the drug formulary as part of an integrated patient care process, which enables health care professionals to work together to promote clinically sound, safe, and cost-effective medication therapy. This system incorporates drug utilization review services by pharmacists to screen patient data to evaluate safety and appropriateness of medication use ultimately to avoid harm. ${ }^{3}$ 
Veterans Affairs (VA) medical centers use a pharmacy-led formulary management approach and provide reviews of prior authorization drug requests (PADRs) through a pharmacistadjudicated consult service. The service assigns responsibility to pharmacists, since they have an important and foundational role in decreasing medication misuse and optimizing drug therapy. Pharmacist-led interventions and recommendations are valuable to help minimize adverse drug events (ADEs) and prevent medication errors from reaching a patient and have been demonstrated in many different practice settings. ${ }^{3-8}$

Pharmacists not only create a safety effect for patients, but also an economic effect because of interventions made to prevent ADEs. The economic value of pharmacy services in various health care settings to prevent ADEs has been established in many different practice settings, ${ }^{5,7-11}$ including interventions made with the intention to avoid potential ADEs, which can be assessed for cost avoidance. One such demonstration was a retrospective analysis of decentralized surgical intensive care unit clinical pharmacist interventions at a tertiary care institution; $85 \%$ of the interventions prevented a potential ADE, and overall cost avoidance was determined to be between $\$ 205,919$ and $\$ 280,421 .^{11}$

A similar yet unique opportunity may be seen through a pharmacist-led PADR consult service by identifying the economic benefit of safety interventions made to prevent the occurrence of ADEs. Economic outcomes associated with prevention of ADEs have not previously been demonstrated in the setting of a pharmacist-adjudicated PADR consult service. Thus, the primary objective of this study was to evaluate the cost avoidance associated with safety interventions of a pharmacist-adjudicated PADR consult service within a VA health care system. The secondary objectives were to evaluate direct cost savings associated with the PADRs not approved due to a safety intervention, evaluate cost avoidance and direct cost savings based on clinical specialty of a pharmacist adjudicating a PADR, and to characterize the severity of prevented ADEs.

\section{Methods}

\section{Practice Setting Description}

The pharmacist-led PADR consult service is located within the formulary management department in the pharmacy of the Durham VA Health Care System, which is a 271-bed tertiary care health care system and serves as a referral, teaching, and research facility. The health care system provides general, specialty medical, surgical, inpatient, and outpatient services. Several community-based outpatient clinics operate under the medical center to provide expanded access to care for veterans in broader geographical areas with travel limitations.

The pharmacist-led formulary management approach for adjudication of PADRs is managed by a pharmacist team consisting of 2.5 full-time equivalents (FTE). Decentralized pharmacist teams adjudicate PADRs related to their respective clinical practice setting. The decentralized teams include 3.6 anticoagulation, 2.8 inpatient, 1 oncology, and 2 infectious diseases pharmacist FTEs.

Using the VA National Formulary, our institution requires electronic PADR consults to be submitted for medications that are nonformulary or formulary with local restrictions. Formulary-restricted drugs are determined by the national Pharmacy Benefits Management Services (PBM) or local pharmacy and therapeutics committees. The PADRs are developed from national VA clinical guidance documents published by the PBM, which may be associated with specific criteria for use. Once PADRs are submitted by a provider, a pharmacist reviews for appropriateness and safety (adjudication) before the drug can be filled and dispensed by the pharmacy. The review is expected to be completed within 96 hours to ensure timely access to medications. This process also allows for dialogue between the adjudicating pharmacist and provider to determine if the veteran is an appropriate candidate for the requested medication.

\section{Study Design}

This study was a single-center, institutional review boardapproved, retrospective chart review using the VA system's Computerized Patient Record System to identify PADRs that were not approved due to a safety intervention by a pharmacist within the Durham VA Health Care System between July 1, 2016, and June 30, 2017. PADRs that were approved, contained incomplete documentation, or were not approved due to a nonsafety intervention were excluded.

Data were collected and reviewed on all eligible PADRs and included patient- and PADR-specific information. Patientspecific data points included age, gender, and race. PADRspecific data points included formulary status, requested medication regimen, inpatient or outpatient status, drug costs for requested and alternative therapy, clinical specialty team adjudicating PADR, PADR requestor classification, safety intervention, and rationale resulting in nonapproved PADRs. Safety intervention categories included prevent or manage ADE, drug interaction, drug not indicated, or prevent or manage a drug allergy. ${ }^{12}$

\section{Study Endpoints}

Cost avoidance associated with ADEs avoided was assessed as the primary endpoint. Cost avoidance was calculated by multiplying the probability of the ADE occurring in the absence of the PADR safety intervention by the estimated cost avoided based on the intervention category. The probability of the ADE occurring in the absence of the PADR safety intervention was classified as none (0), very low (0.01), low (0.1), medium (0.4), or high (0.6). ${ }^{13,14}$ The PADR was assigned to a probability category based on the prevalence percentage of an $\mathrm{ADE}$ occurring as determined in the literature (i.e., primary or 


\section{TABLE 1 PADR Characteristics ( $N=96)$}

\begin{tabular}{|c|c|c|}
\hline \multicolumn{3}{|l|}{ Patient demographics } \\
\hline Age in years, mean (range) & 67.3 & $(28-96)$ \\
\hline Male gender, n (\%) & 92 & $(95.8)$ \\
\hline \multicolumn{3}{|l|}{ Race, n (\%) } \\
\hline Caucasian & 57 & $(59.4)$ \\
\hline African American & 35 & $(36.5)$ \\
\hline American Indian/Alaska native & 2 & $(2.1)$ \\
\hline Other & 2 & $(2.1)$ \\
\hline \multicolumn{3}{|l|}{ Requesting provider classification, $\mathrm{n}$ (\%) } \\
\hline Attending physician & 49 & $(51.0)$ \\
\hline Medical trainee & 28 & $(29.2)$ \\
\hline Physician assistant/nurse practitioner & 19 & $(19.8)$ \\
\hline \multicolumn{3}{|c|}{ Clinical specialty of adjudicating pharmacist, $\mathrm{n}(\%)$} \\
\hline Anticoagulation & 47 & $(49.0)$ \\
\hline Formulary management & 27 & $(28.1)$ \\
\hline Infectious diseases & 9 & (9.4) \\
\hline Oncology & 9 & $(9.4)$ \\
\hline Inpatient & 4 & $(4.2)$ \\
\hline \multicolumn{3}{|l|}{ Safety intervention, $\mathrm{n}(\%)$} \\
\hline Prevent or manage adverse drug event & 61 & $(63.5)$ \\
\hline Drug interaction & 17 & $(17.7)$ \\
\hline Drug not indicated & 16 & $(16.7)$ \\
\hline Prevent or manage drug allergy & 2 & $(2.1)$ \\
\hline
\end{tabular}

tertiary references), or if explicitly relevant, the Nesbit method examples were used as described by Gallagher et al. (2014).14,15 For example, a PADR was placed for palbociclib therapy for a veteran with stage IV breast cancer and pre-existing neutropenia. Thus, the inappropriate addition of palbociclib may have resulted in worsening neutropenia, since the incidence of neutropenia with this medication is $80 \%-83 \%$ for all grades. ${ }^{16}$ For this example, the likelihood of an ADE occurring would be classified as high (0.6). Cost avoided per recommendation was determined based on the categorization of the intervention (i.e., drug interaction, drug not indicated for use, prevention or management of drug allergy, or prevention or management of $\mathrm{ADE}$ ) and practice setting (i.e., inpatient or outpatient setting). ${ }^{12}$ All assigned costs obtained from previous literature were adjusted for inflation. ${ }^{12,17}$

Direct cost savings and severity of ADEs avoided were assessed as secondary endpoints. Direct cost savings were determined by totaling the cost of requested medications not approved for each PADR and subtracting the cost of recommended alternative therapies and cost of pharmacist PADR review. Cost of requested therapy and cost of recommended alternative therapy factored in daily drug acquisition costs and duration of therapy. ${ }^{8}$ Drug pricing data were obtained from VA internal pharmacy systems. Alternative therapies recommended were based on clinical judgment of the adjudicating pharmacist, VA National Formulary requirements, or local

\begin{tabular}{|c|c|c|c|}
\hline TABLE 2 & $\begin{array}{l}\text { Cost Avoida } \\
\text { Pharmacist- } \\
\text { Intervention }\end{array}$ & $\begin{array}{l}\text { nce Associat } \\
\text { Adjudicated } \\
\text { s }\end{array}$ & $\begin{array}{l}\text { with } \\
\text { DR Safety }\end{array}$ \\
\hline $\begin{array}{l}\text { ADE Intervention } \\
\text { Category }\end{array}$ & $\begin{array}{c}\text { Cost Avoidance } \\
\text { Value, }{ }^{12,17} \$\end{array}$ & $\begin{array}{c}\text { ADE Probability } \\
\text { Score }\end{array}$ & $\begin{array}{c}\text { Cost } \\
\text { Avoidance, \$ }\end{array}$ \\
\hline Drug interaction & 428.30 & $0.6(n=17)$ & $4,368.66$ \\
\hline \multirow[t]{3}{*}{ Drug not indicated } & \multirow[t]{3}{*}{98.63} & $0.1 \quad(n=5)$ & 49.32 \\
\hline & & $0.4 \quad(n=8)$ & 315.62 \\
\hline & & $0.6 \quad(n=3)$ & 177.53 \\
\hline \multirow{3}{*}{$\begin{array}{l}\text { Prevent or manage } \\
\text { adverse drug event }\end{array}$} & \multirow[t]{3}{*}{724.19} & $0.1 \quad(n=2)$ & 144.84 \\
\hline & & $0.4(n=45)$ & $13,035.42$ \\
\hline & & $0.6(n=14)$ & $6,083.20$ \\
\hline \multirow{2}{*}{$\begin{array}{l}\text { Prevent or manage } \\
\text { drug allergy }\end{array}$} & \multirow[t]{2}{*}{310.75} & $0.4(n=1)$ & 124.30 \\
\hline & & $0.6 \quad(n=1)$ & 186.45 \\
\hline & & & Total: $24,485.34$ \\
\hline
\end{tabular}

$A D E=$ adverse drug event; $P A D R=$ prior authorization drug request.

formulary status restrictions. If multiple alternative therapy recommendations were made with a clear absence of preferred agent, an average cost was calculated. If no alternative therapy was recommended, the cost was assigned $\$ 0$. Durations of therapy were determined based on preset definitions. Cost of PADR review involved multiplying pharmacist labor costs (derived by pharmacist average hourly salary with benefits ${ }^{10}$ ) and the duration of time spent on PADR intervention.

Severity estimates of ADEs avoided were classified as minor, moderate, major, or catastrophic. Minor severity was defined as an ADE that requires no intervention or minimal therapeutic intervention (i.e., discontinuation of drug); moderate severity was defined as an ADE that requires active treatment, further testing, or evaluation to assess extent of nonserious outcome; major severity was defined as an ADE that results in a serious patient outcome (i.e., life-threatening condition, hospitalization, or increased length of stay); and catastrophic severity was defined as ADE results in death or permanent loss of function, disability, or congenital anomaly. ${ }^{18,19}$

All potential ADEs avoided were reviewed by a panel of 3 board-certified clinical pharmacists to validate ADE classification and ADE probability and severity scores. The individual collecting ADE data was not a panel member. Two panel members reviewed and scored the ADE individually, and disagreements were resolved by a third panel member. Descriptive statistics were used for all assessments.

\section{Results}

Of the 910 PADRs not approved during the study period, 812 were excluded because of nonsafety interventions, and 2 were excluded because of incomplete documentation. A total of 96 PADRs met inclusion criteria and were analyzed. All PADRs meeting inclusion criteria were for outpatient use. The patient population associated with the PADRs included were majority 
FIGURE 1 Economic Outcomes Based on Clinical Specialty of the Adjudicating Pharmacist

\section{A. Cost Avoidance, $\$$}

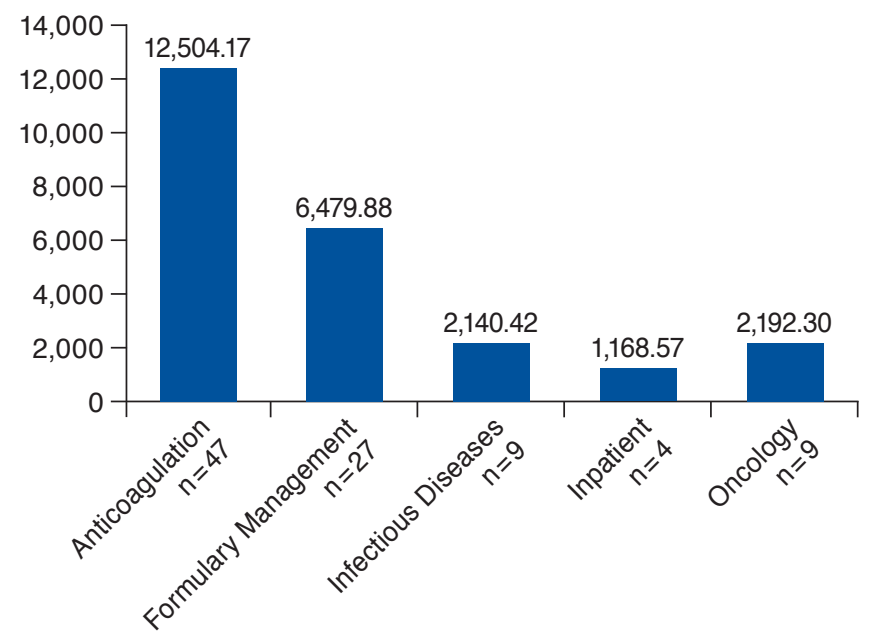

B. Direct Cost Savings, \$

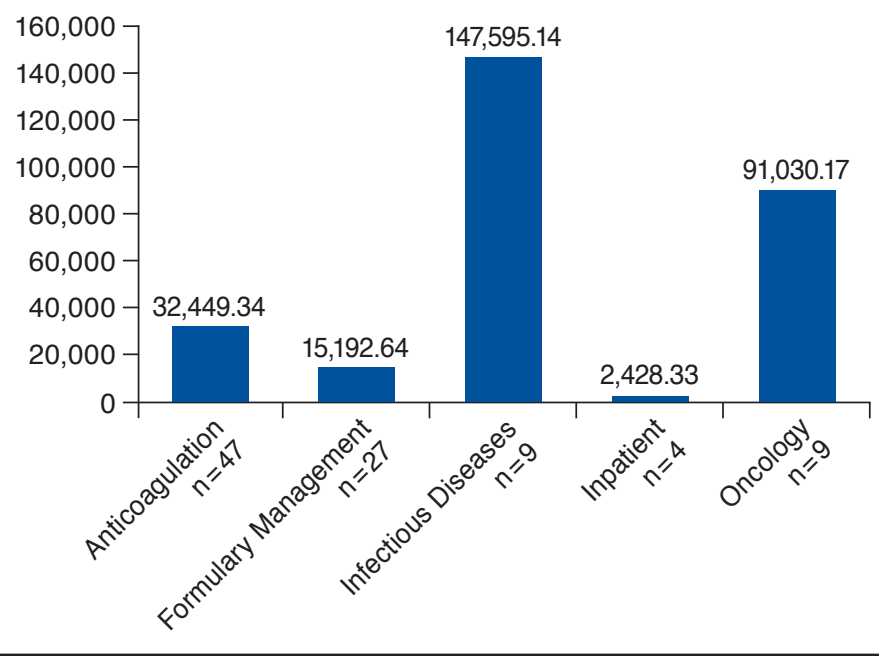

male, Caucasian, and had a mean age of 67 years (Table 1). Providers placing PADRs were most frequently attending physicians. The clinical specialty team making the most safety interventions was anticoagulation, and the most frequent safety interventions made were to prevent or manage an ADE.

Cost avoidance associated with prevented ADEs was determined to be $\$ 24,485.34$ (mean: $\$ 255.06$; range: $\$ 9.86-\$ 434.51$ ). Distribution of PADRs within the probability scale used to determine cost avoidance calculation ranged between low (7.3\%), medium (56.3\%), or high (36.5\%). Table 2 summarizes the ADE probability classification distribution attributed to each applicable ADE intervention category. Cost avoidance per clinical specialty of the adjudicating pharmacist is illustrated in Figure 1A.

Overall direct cost savings was $\$ 288,695.63$ (mean: $\$ 3,007.25$; range: $-\$ 32,830.47-\$ 130,738.53$; Table 3 ). There was a total of 20 PADRs that resulted in a negative direct cost savings due to a higher cost of the recommended alternative therapy. Direct cost savings per clinical specialty of the adjudicating pharmacist is illustrated in Figure 1B. The severity categories for the prevented ADEs were determined to be minor (7.3\%), moderate (24.0\%), major (64.6\%), and catastrophic (4.2\%). Representative examples of PADRs evaluated for probability and severity scores are included in the Appendix (available in online article).

\section{Discussion}

The results of these PADR economic and safety analyses demonstrate the effect of a pharmacist-led PADR consult service. During the study period, the institution would have had the potential to incur an additional cost of $\$ 24,485.34$ for management of safety-related events in the absence of the safety interventions by pharmacists adjudicating PADRs. Anticoagulation PADRs had the highest contribution to cost avoidance likely due to working with high-alert medications such as enoxaparin or warfarin. These results add value to the current literature, since there is a lack of cost avoidance analysis data for safety interventions within the veteran population and in a pharmacist-adjudicated PADR consult service setting. In addition, over two thirds of the safety interventions were made to avoid major or catastrophic ADEs.

PADRs not approved based on pharmacist safety interventions resulted in an overall direct cost savings of $\$ 288,695.63$ after accounting for cost of alternative therapy recommended and pharmacist labor cost. Because these analyses represent PADR safety reviews only, these data are a small representation among all PADRs reviewed by pharmacists. PADRs not approved for alternative reasons such as preferred therapeutic alternatives not exhausted or for optimization of formulary agent give rise to further cost savings potential. Britt et al. (2016) showed that 198 PADRs not approved for nonsafety (81.3\%) and safety (18.7\%) rationales in a similar setting resulted in a total cost savings of $\$ 434,738.84$ over a 3-month period..$^{10}$ With the extrapolation of this cost savings data over an annual period and the cost avoidance analysis conducted specifically on PADR safety interventions, pharmacist involvement within a pharmacist-adjudicated PADR consult service easily justifies the cost of implementing the service within a health care system.

The infectious diseases clinical pharmacists demonstrated the highest direct cost savings during the study period. This is likely because of the high drug costs of antiviral therapies but 
TABLE 3 Direct Cost Savings per Clinical Specialty of the Adjudicating Pharmacist

\begin{tabular}{|c|c|c|c|c|c|c|c|}
\hline & \multicolumn{2}{|c|}{ Cost of Therapy, \$ } & \multicolumn{5}{|c|}{ Direct Cost Savings, $\$$} \\
\hline & $\begin{array}{l}\text { Total as } \\
\text { Requested }\end{array}$ & $\begin{array}{l}\text { Total After } \\
\text { Review }^{\mathrm{a}}\end{array}$ & Total & $\begin{array}{l}\text { Mean per } \\
\text { Request }\end{array}$ & $\begin{array}{l}\text { Median per } \\
\text { Request }\end{array}$ & $\begin{array}{l}\text { Minimum per } \\
\text { Request }\end{array}$ & $\begin{array}{l}\text { Maximum per } \\
\text { Request }\end{array}$ \\
\hline Anticoagulation $(n=47)$ & $41,941.05$ & $9,491.71$ & $32,449.34$ & 691.48 & 968.77 & $-1,193.38$ & $1,063.67$ \\
\hline Formulary management $(n=27)$ & $16,533.10$ & $1,340.46$ & $15,192.64$ & 562.69 & 177.87 & -125.08 & $3,156.27$ \\
\hline Infectious diseases $(\mathrm{n}=9)$ & $213,837.57$ & $66,242.43$ & $147,595.14$ & $16,399.46$ & $13,298.69$ & $-32,830.47$ & $130,738.53$ \\
\hline Inpatient $(n=4)$ & $2,538.10$ & 109.77 & $2,428.33$ & 607.08 & 618.15 & 79.77 & $1,112.27$ \\
\hline Oncology $(n=9)$ & $203,136.94$ & $112,106.77$ & $91,030.17$ & $10,114.46$ & $4,991.08$ & $-32,551.68$ & $56,891.78$ \\
\hline Total $(\mathrm{N}=96)$ & $477,986.76$ & $189,291.13$ & $288,695.63$ & $3,007.25$ & 968.77 & $-32,830.47$ & $130,738.53$ \\
\hline
\end{tabular}

was also influenced by the PADRs with negative cost savings in other clinical settings. In total, 20 PADRs resulted in negative direct cost savings due to pharmacists recommending alternative therapies more expensive than the requested therapy. This finding may suggest that pharmacists likely prioritized clinical appropriateness when adjudicating the PADRs over alternative reasons such as drug costs. The pharmacist's role as drug expert within a formulary management system not only prevents potential ADEs or medication errors but also ensures that medications are selected based on safety and efficacy over cost.

\section{Limitations}

This assessment has several limitations to consider. Because of the retrospective nature of the analysis and the fluctuations in contract pricing, medication acquisition costs obtained during data collection may have been slightly different compared with when the PADRs were originally submitted. The use of VA contract pricing may also be lower than non-VA facilities, so direct cost savings may be underestimated compared with non-VA institutions. In addition, the overall analysis may have underestimated safety interventions. For example, clinical pharmacists may have made verbal or written safety interventions directly with a provider, which prevents a PADR submission in the first place; therefore, these interventions were not captured or reflected in this assessment.

The cost avoidance calculation used in our analysis was an adaptation from 2 previous publications, ${ }^{12,14} 1$ of which assessed cost avoidance based on a VA pricing model. ${ }^{12}$ The actual cost that our institution could incur for an ADE is unknown; therefore, this estimation was used, and the results were adjusted for inflation. Furthermore, for probability of ADEs avoided, severity and cost avoidance value categories were estimated and assigned based on subjective assessment and clinical judgement.

To mitigate the potential for investigator bias, an independent panel of 3 clinically experienced board-certified pharmacists validated all determinations. In addition, the potential costs associated with an ADE occurring due to the recommended alternative medications were not assessed. Finally, had an ADE occurred, the negative effect on the patient was not captured beyond cost savings and cost avoidance to the institution.

\section{Conclusions}

Safety-related interventions by a pharmacist-adjudicated PADR consult service may have resulted in substantial cost avoidance and cost savings. The majority of safety interventions had the potential to prevent major ADEs as determined by a panel of pharmacists. These analyses support the pharmacist's role in a formulary management system to optimize medication therapy.

\section{Authors}

SHERIN JACOB, PharmD, BCPS; RACHEL B. BRITT, PharmD, BCPS; WILLIAM E. BRYAN, PharmD, BCPS; MOHAMED G. HASHEM, PharmD, BCPS; JONATHAN C. HALE, PharmD, BCPS; and JAMIE N. BROWN, PharmD, BCPS, BCACP, Pharmacy Department, Durham Veterans Affairs Health Care System, Durham, North Carolina.

AUTHOR CORRESPONDENCE: Sherin Jacob, PharmD, BCPS, Pharmacy Department, James J. Peters VA Medical Center, 130 W. Kingsbridge Rd., Bronx, NY 10468. Tel.: 718.584.9000; E-mail: sherin.jacob18@va.gov.

\section{DISCLOSURES}

This research did not receive any specific grant from funding agencies in the public, commercial, or not-for profit sectors. The authors have nothing to disclose.

\section{REFERENCES}

1. American Hospital Association, Health Research and Educational Trust, Institute for Safe Medication Practices. Pathways for medication safety: leading a strategic planning effort. 2002. Available at: https://www.ismp.org/ sites/default/files/attachments/2017-11/PathwaySectionl-Leadership.pdf. Accessed January 7, 2019

2. American Society of Hospital Pharmacists. ASHP guidelines on preventing medication errors in hospitals. Am J Hosp Pharm. 1993;50(2):305-14. 
3. Academy of Managed Care Pharmacy. Formulary management. November 2009. Available at: http://www.amcp.org/WorkArea/DownloadAsset. aspx?id=9298. Accessed January 7, 2019.

4. Groppi JA, Ourth H, Morreale AP, Hirsh JM, Wright S. Advancement of clinical pharmacy practice through intervention capture. Am J Health Syst Pharm. 2018;75(12):886-92.

5. Cohen V, Jellinek SP, Hatch A, Motov S. Effect of clinical pharmacists on care in the emergency department: a systematic review. Am J Health Syst Pharm. 2009;66(15):1353-61.

6. Bonetti AF, Reis WC, Lombardi NF, et al. Pharmacist-led discharge medication counselling: a scoping review. J Eval Clin Pract. 2018;24(3):570-79.

7. Hamblin S, Rumbaugh K, Miller R. Prevention of adverse drug events and cost savings associated with PharmD interventions in an academic

level 1 trauma center: an evidence-based approach. J Trauma Acute Care Surg. 2012;73(6):1484-90

8. Dalton K, Byrne S. Role of the pharmacist in reducing healthcare costs: current insights. Integr Pharm Res Pract. 2017;6:37-46.

9. Bates DW, Spell N, Cullen DJ, et al. The costs of adverse drug events in hospitalized patients. JAMA. 1997;277(4):307-11.

10. Britt RB, Hashem MG, Bryan WE, Kothapalli R, Brown JN. Economic outcomes associated with a pharmacist-adjudicated formulary consult service in a Veterans Affairs medical center. J Manag Care Spec Pharm. 2016;22(9):1051-56. Available at: https://www.jmcp.org/doi/10.18553/ jmcp.2016.22.9.1051

11. Kopp BJ, Mrsan M, Erstad BL, Duby JJ. Cost implications of potential adverse events prevented by interventions of a critical care pharmacist. Am J Health Syst Pharm. 2007;64(23):2483-87.
12. Lee AJ, Boro MS, Knapp KK, Meier JL, Korman NE. Clinical and economic outcomes of pharmacist recommendations in a Veterans Affairs medical center. Am J Health Syst Pharm. 2002;59(21):2070-77.

13. Johnson JA, Bootman JL. Drug-related morbidity and mortality: a cost of illness model. Arch Intern Med. 1995;155(18):1949-56.

14. Nesbit TW, Shermock KM, Bobek MB, et al. Implementation and pharmacoeconomic analysis of a clinical staff pharmacist practice model. Am J Health Syst Pharm. 2001;58(9):784-90.

15. Gallagher J, Byrne S, Woods N, Lynch D, McCarthy S. Cost-outcome description of clinical pharmacist interventions in a university teaching hospital. BMC Health Serv Res. 2014;14:177.

16. Truven Health Analytics, IBM Watson Health. Palbociclib. In: IBM Micromedex. Database. Available at: http://www.micromedexsolutions.com/ micromedex2/librarian/. Accessed January 7, 2019.

17. Bureau of Labor Statistics. CPI inflation calculator. Retrieved July 19, 2017. Available at: https://www.bls.gov/data/inflation_calculator.htm. Accessed January 7, 2019.

18. Campbell AR, Nelson LA, Elliott E, Hieber R, Sommi RW. Analysis of cost avoidance from pharmacy students' clinical interventions at a psychiatric hospital. Am J Pharm Educ. 2011;75(1):8.

19. Department of Veterans Affairs, Veterans Health Administration. The safety assessment code (SAC) matrix. Appendix B. VHA Handbook 1050.01. March 2011. Available at: https://www.va.gov/vhapublications/ ViewPublication.asp?pub_ID=2389. Accessed January 17, 2019.

\begin{tabular}{|c|c|c|c|c|}
\hline Requested Drug & $\begin{array}{c}\text { Recommended } \\
\text { Alternative Therapy }\end{array}$ & Safety Intervention Rationale & Probability Score & Severity Score \\
\hline Lidocaine patch & No lidocaine patch & Not indicated for patient with pain associated with fistula & 0.1 & Minor \\
\hline Fenofibrate & No fenofibrate & Contraindicated due to patient liver function abnormalities & 0.1 & Moderate \\
\hline Rivaroxaban & Warfarin & $\begin{array}{l}\text { Not indicated for patient with multiple brain infarcts with } \\
\text { possible source from cardiac tumor }\end{array}$ & 0.1 & Major \\
\hline Sacubitril/valsartan & $\begin{array}{l}\text { No sacubitril/ } \\
\text { valsartan }\end{array}$ & $\begin{array}{l}\text { Patient's heart failure regimen was being titrated and must be } \\
\text { stable for at least } 4 \text { weeks before treatment }\end{array}$ & 0.4 & Minor \\
\hline Empaglifozin & No empaglifozin & Patient with hemoglobin Alc at $6.2 \%$ (goal $<7.0 \%)$ & 0.4 & Moderate \\
\hline Ticagrelor & Clopidogrel & $\begin{array}{l}\text { Patient at a higher risk of bleed due to chronic anticoagulation } \\
\text { with warfarin }\end{array}$ & 0.4 & Major \\
\hline Pregabalin & No pregabalin & $\begin{array}{l}\text { Patient with history of multiple suicide attempts without } \\
\text { clearance from mental health provider }\end{array}$ & 0.4 & Catastrophic \\
\hline $\begin{array}{l}\text { Sofosbuvir/ } \\
\text { velpatasvir }\end{array}$ & $\begin{array}{l}\text { Daclatasvir + } \\
\text { sofosbuvir }\end{array}$ & $\begin{array}{l}\text { Patient has a drug interaction with omeprazole and does not have } \\
\text { required baseline NS5A resistance testing }\end{array}$ & 0.6 & Minor \\
\hline Sorafenib & No sorafenib & Contraindicated in patient with Child-Turcotte-Pugh Class C & 0.6 & Moderate \\
\hline Rivaroxaban & Warfarin & Patient has a drug interaction contraindication with primidone & 0.6 & Major \\
\hline
\end{tabular}

